\title{
JOSEP-IGNASI SARANYANA: SU APORTACIÓN MEDIEVALISTA
}

\author{
José Ángel García Cuadrado \\ Universidad de Navarra
}

El 5 de mayo de 2011 se celebró en la Facultad de Teología de la Universidad de Navarra el acto académico en homenaje al profesor Josep-Ignasi Saranyana Closa, con motivo de su jubilación. Fue, sin duda, un merecido reconocimiento a sus cuarenta años de dedicación a la docencia e investigación en esa institución universitaria, de la que se han beneficiado no sólo sus alumnos y colegas de claustro, sino también otros muchos investigadores y docentes de muy diversas procedencias. Durante ese acto se le hizo entrega del último número de la revista Anuario de Historia de la Iglesia - de la que fue su primer director-, en donde se recogen diversas contribuciones acerca de su vida y obra. Se recibieron numerosas adhesiones al homenaje provenientes de diversas instituciones universitarias, así como de personalidades internacionales del mundo de la cultura y de la Iglesia. Un vistazo a esas cartas y mensajes de adhesión da idea de la fecundidad y alcance de la obra del profesor Saranyana, no sólo en el ámbito del pensamiento medieval, sino también en el de la historiografía de la Teología latinoamericana.

La Revista española de Filosofía Medieval - de la que fue impulsor tenaz desde sus orígenes - quiere sumarse a este homenaje con motivo de su jubilación mediante el presente artículo en el que se apuntarán algunos aspectos de la investigación medievalista del profesor Saranyana. Este apunte acerca de su pensamiento será necesariamente incompleto, no sólo porque con su jubilación no se ha cerrado su labor investigadora - ahora desde su Barcelona natal - sino porque sería preciso un análisis más extenso y detenido de su amplia producción, así como del alcance de los múltiples proyectos que ha impulsado a lo largo de su vida académica. Consciente de las limitaciones de mi exposición, desearía al menos que contribuyera a manifestar mi agradecimiento personal y admiración por uno de los medievalistas del ámbito hispano más destacados en la actualidad. ${ }^{1}$

\section{PERFIL BIOGRÁFICO Y ACADÉMICO²}

Josep-Ignasi Saranyana nació en la Ciudad Condal el 20 de junio de 1941. Hasta 1954 estudió en la Escuela Suiza de Barcelona y prosiguió sus estudios de bachillerato en el Ins-

1 Una exposición más detenida y amplia de las principales contribuciones de nuestro autor a los estudios medievales puede encontrarse en el artículo de M. a Jesús Soto BRUNA, «Presencia y manifestación del medievo. Contribuciones de Josep-Ignasi Saranyana al pensamiento medieval», Anuario de Historia de la Iglesia, 20 (2011), pp. 73-97.

2 Para las cuestiones biográficas resulta de gran utilidad la entrevista con el periodista Gabriel Pérez, publicada en Anuario de Historia de la Iglesia, 20 (2011), pp. 17-54. 
tituto Superior de Enseñanza Media «Menéndez y Pelayo». En 1959 comienza sus estudios en Ciencias Políticas y Económicas en la Universidad de Barcelona, concluidos los cuales marchó a Roma para cursar los estudios filosófico-teológicos. Regresó a España y en octubre de 1967 empezó a estudiar en el Instituto Teológico de la Universidad de Navarra — de muy reciente creación - , para obtener los grados en Teología. Terminado el primer año de licenciatura recibió la ordenación sacerdotal el 25 de agosto de 1968. Se licenció en Teología en junio de 1969, y en octubre de 1972 defendió su tesis doctoral bajo la dirección del Profesor Pedro Rodríguez. La tesis fue publicada posteriormente bajo el título El tiempo y la eternidad. Estudio sobre la Teología de la historia en San Buenaventura. En esa fecha se incorporó al claustro académico de la Facultad de Teología en dicha Universidad.

A mediados de la década de los ochenta comenzó sus investigaciones en el campo de la Historia de la Teología Latinoamericana que culminaron en una monografía monumental en cuatro volúmenes, ${ }^{3}$ en la que han intervenido veintinueve académicos, adscritos a diecinueve centros universitarios (cinco europeos y catorce latinoamericanos). Este trabajo - llevado a cabo sobre fuentes primarias - , muestra cómo la Teología latinoamericana nació de un tronco común teológico, de carácter latino-europeo, hasta la irrupción de teologías latinoamericanistas en el año 1971. El éxito de la evangelización no se debió, por tanto, a la «creación» de una teología nueva con relación al tronco común, sino a la vitalidad de la teología pretridentina y, más todavía, a la misma reforma auspiciada por Trento. ${ }^{4}$ Este proyecto de investigación se ha visto recientemente completado con un manual para uso escolar. ${ }^{5}$

Durante esos años de investigación americanista no abandonó los estudios medievales comenzados con su doctorado en Teología. Fruto de su dilatada docencia es el manual de Historia de la Filosofía medieval que ha conocido numerosas reediciones, ${ }^{6}{ }^{\text {así como numerosas }}$ monografías y artículos especializados sobre la filosofía y teología medieval, y en particular sobre Joaquín de Fiore, Anselmo de Aosta, Avicena, Averroes, Buenaventura, Tomás de Aquino, Ockham y Duns Escoto, entre otros. Se doctoró en Filosofía por la Pontificia Universidad de Salamanca, con una tesis titulada La discusión medieval sobre la condición femenina (siglos VIII al XIII), dirigida por Francisco Rodríguez Pascual. También es Diplomado en Estudios Americanos por la Universidad Hispanoamericana de Santa María de la Rábida, e investigador científico de «Historia de la Teología en España», del Consejo Superior de Investigaciones Científicas (Madrid). Ha dirigido 69 tesis doctorales, de las que 36 se centran en temas medievales. ${ }^{7}$ En 1992 puso en marcha la revista Anuario de Historia de la Iglesia. En el año 1999 fue nombrado miembro del Pontificio Comité de Ciencias Históricas (Roma). Además, desde 2001, es columnista habitual de La Vanguardia. Y habría que mencionar también la extensa labor pastoral en su ministerio sacerdotal que ha desarrollado a lo largo de todos estos años de dedicación a las tareas universitarias.

3 Josep-Ignasi Saranyana (dir.) - Carmen-José Alejos Grau (coord.), Teología en América Latina, Madrid Frankfurt, Iberoamericana - Vervuert, 1999-2008, 4 vols., 3.553 pp.

4 Para una explicación más detallada de la aportación americanista del Prof. Saranyana puede consultarse el artículo de Fernando ARmAs Asín, «Teología y vida. La producción americanista de Josep-Ignasi Saranyana (19842010)», en Anuario de Historia de la Iglesia, 20 (2011), pp. 55-71.

5 Josep-Ignasi Saranyana, Breve historia de la teología en América Latina, Bac, Madrid, 2009.

6 Publicado por vez primera en 1985, ha alcanzado ya seis ediciones, las dos últimas llevan otro título: $L a$ filosofía medieval. Desde sus orígenes patrísticos hasta la Escolástica barroca, EUnSA («Colección Pensamiento filosófico medieval y renacentista», 51), Pamplona, 2003. 2a edición revisada y aumentada, 2007. Trad. portuguesa: Instituto Brasileiro de Filosofia e Ciência «Raimundo Lúlio», São Paulo, 2006.

7 El curriculum completo puede consultarse en la siguiente dirección web: www.unav.es/thistorica/ curriculum/saranyana/default.html 


\section{FE Y RAZÓN, FILOSOFÍA Y TEOLOGÍA EN LA EDAD MEDIA}

El homenaje al profesor Saranyana antes mencionado, vino precedido de una jornada académica en su honor en la que intervinieron Ángel Luis González (Facultad de Filosofía y Letras de la Universidad de Navarra), que trató sobre «Nicolás de Cusa: Filosofía, Teología y Mística»; el profesor Manuel Lázaro Pulido (Instituto de Filosofía de la Facultad de Letras de la Universidad de Oporto), que habló acerca de «Cómo filosofa san Buenaventura cuando hace Teología»; y el doctor Víctor Sanz (Universidad de Navarra) que centró su exposición en «Filosofía y Teología en Francisco Suárez». Pocas semanas antes, el mismo profesor Saranyana había pronunciado en esa misma sede la conferencia con motivo de la festividad de Santo Tomás, bajo el título: «Cómo filosofa Tomás de Aquino cuando hace Teología». Resulta ciertamente ilustrativo que sea precisamente esta cuestión fronteriza entre filosofía y teología el tema elegido como colofón de su vida académica.

En su manual sobre La Filosofía Medieval, Saranyana recorre la historia de la historiografía medieval inaugurada en el racionalismo francés. Reconoce el valor de sus aportaciones señalando el marco doctrinal que los anima: «Los primeros historiadores racionalistas que se aplicaron, en el siglo XIX (Victor Cousin, Jean-Barthélemy Hauréau, François Picavet, Leon Gauthier y Émile Verrier) consideraron que lo propio de las especulaciones escolásticas medievales fue su desarrollo bajo la tutela de la Iglesia. Esto habría supuesto, según ellos, un aspecto negativo y otro positivo. El negativo sería haber paralizado el esfuerzo filosófico, al vincular la libertad de las investigaciones, a una verdad heterónoma, de origen divino, dispensando al hombre de un esfuerzo personal serio por resolver racionalmente algunos misterios. Desde su perspectiva positiva, los citados historiadores apreciaron la aparición, en la Edad Media, de la especulación religiosa, es decir, de la ciencia teológica, a la que respetaban, aunque no la consideraban propiamente filosófica, ni, en última instancia, rigurosamente científica». ${ }^{8}$ Saranyana se hace cargo de las posturas racionalistas, pero sus esfuerzos se han dirigido a reivindicar el valor filosófico de las doctrinas de los teólogos medievales: «La mayor parte de las polémicas medievales de carácter filosófico se producen para resolver problemas teológicos».

Según Saranyana, la Edad Media está marcada desde sus orígenes por la apropiación receptiva del pensamiento antiguo y patrístico, que al fundirse con la revelación bíblica va gestando una cosmovisión original. En este sentido, los pensadores medievales se abren a la tradición clásica y a la autoridad de autores paganos (Platón, Aristóteles) junto a las primeras elaboraciones de la Patrística (especialmente San Agustín). Saranyana reivindica el valor de la tradición de las Escuelas y de la fecunda relación entre ellas. El fundamento de esta reivindicación de la tradición reside en el papel que ocupa la filosofía en esta época. «Para la Edad Media, en efecto, el filosofar no tiene la dirección subjetiva que toma en la modernidad; de tal modo que su mirada al pasado no es especular: no le devuelve su propia imagen, sino la realidad de una historia por asumir. Se entiende a partir de lo anterior que, una vez hallada la verdad en filosofía, ésta debe ser continuada. Por ello, el papel de la razón no resulta entonces superfluo o sin significación». ${ }^{10}$ Con sus publicaciones, Saranyana hace ver que el examen de la historia de la filosofía medieval es intrínsecamente filosófico, a la vez que entra de lleno en las cuestiones de la dogmática y de la teología. En definitiva, como subrayó en la conferencia antes citada sobre el modo de filosofar de Santo Tomás, el filósofo creyente debe preservar el

8 Josep-Ignasi Saranyana, La Filosofía Medieval, p. 26.

9 Josep-Ignasi Saranyana, Sobre el tiempo y la eternidad, Gráficas Egúzquiza, Pamplona, 1976, p. 8.

10 M. Jesús Soто, «Presencia y manifestación del medievo. Contribuciones de Josep-Ignasi Saranyana al pensamiento medieval», p. 84 . 
estatuto propio de la Filosofía cuando hace Teología. Santo Tomás llegó a la firme convicción - concluía nuestro autor - que tanto en el filosofar autónomo como en el filosofar ancilar o auxiliar de la Teología, la Filosofía debe ser siempre fiel a ella misma.

\section{FILOSOFÍA MEDIEVAL Y MUNDO MODERNO}

La investigación de Josep-Ignasi Saranyana ha contribuido no sólo a una mejor comprensión de los temas filosóficos medievales, sino también a vislumbrar la proyección del pensamiento medieval en la Edad Moderna. Así, por ejemplo, en la segunda parte de su Filosofía medieval, subraya que el despertar del pensamiento renacentista no se podría explicar sin la lenta maduración de la filosofía (y teología) de la Edad Media. Del mismo modo, también el cartesianismo hunde sus raíces en la escolástica, como ya advirtiera en su día Etiénne Gilson. «Por consiguiente, la filosofía medieval no tiene solamente el mérito de hacernos comprender mejor la filosofía moderna; antes bien, tiene su interés propio, en tanto que representa un esfuerzo de pensamiento original. Y si el conocimiento de los filósofos antiguos es una vía inmediata de acceso a la filosofía, el conocimiento de los filósofos medievales puede y debe hacernos jugar el mismo papel, esto es, despertar en nosotros la facultad de pensar». ${ }^{11}$

Se explica así el esfuerzo del medievalista catalán por abrir nuevas líneas de investigación sobre la incidencia del período medieval en el pensar moderno. Muestra de ello es la sugerente vía de estudio abierta en la investigación de las raíces medievales de la antropología de Lutero $^{12}$ - especialmente desde la interpretación de la Carta a los Romanos - , así como sus exposiciones sobre las aportaciones de Occidente a la configuración de la Teología de la América Latina, ${ }^{13}$ o la condición femenina medieval y su proyección en la sociedad moderna. ${ }^{14}$ En todos estos proyectos Saranyana no ha dejado de poner de manifiesto la continuidad entre el pensamiento medieval y la modernidad.

\section{LA REGIONALIZACIÓN DE LA FILOSOFÍA}

Una línea de acercamiento al Medievo filosófico aportada por nuestro autor ha sido su idea de la regionalización de la Filosofía. Se trata de una comprensión de la doctrina de un autor en su contexto histórico y doctrinal, fuera del cual el pensamiento queda muchas veces desconectado de la historia y de la vida. El punto de partida de este acercamiento lo constituye siempre, de modo ineludible, la lectura directa de las obras de un pensador. Pero esa lectura resultaría opaca sin conocer bien la vida y las circunstancias de su quehacer intelectual: «hay que ponerse en la situación del otro para captar su alma».

Sin este esfuerzo por contextualizar históricamente a un autor no se alcanza a comprender, por ejemplo, la síntesis de Duns Escoto al margen de las polémicas desatadas por las

11 Ibidem.

12 Una presentación de este proyecto puede encontrarse en Elisabeth REINHARDT, Nuevas investigaciones sobre Lutero, Anuario de Historia de la Iglesia, 7 (1998), pp. 363-366.

13 Cfr. Josep-Ignasi saranyana, Grandes Maestros de la Teología, I. De Alejandría a México (siglos III al XVI), Prólogo de Melquíades Andrés martín, Madrid, 1994.

14 Cfr. Josep-Ignasi Saranyana, La discusión medieval sobre la condición femenina (siglos VIII al XIII), Salamanca, 1997. En un contexto más amplio había organizado con anterioridad un seminario interdisciplinar «La mujer en la Edad Media»; los trabajos presentados en esa ocasión se publicaron en Anuario Filosófico, 26 (1993), pp. 465-670. 
censuras parisinas de 1277 y de su vocación franciscana. Otro ejemplo lo constituye la obra de Francisco Suárez cuya doctrina resulta ininteligible si se prescinde de las duras controversias entre dominicos y jesuitas. Tampoco se entiende a Juan de Santo Tomás, si se ignora quién fue Cayetano y el influjo que tuvo éste en la Orden Dominicana. Y no es posible hacerse cargo de la síntesis kantiana con independencia del luteranismo, de la revolución científica del siglo XVII y de la revolución de 1688 .

Con todo, no sólo la historia y las circunstancias personales influyen en la elaboración de unas tesis filosóficas y teológicas, sino también el marco geográfico en el que se desarrollan: tal es la tesis de fondo de la regionalización de la filosofía. Fruto de su propuesta es el libro titulado Filosofía y teología en el Mediterráneo occidental (1263-1490). ${ }^{15}$

\section{UNA REVISIÓN DEL TOMISMO}

La investigación del profesor Saranyana recorre sin excepción las grandes escuelas de la tradición escolástica medieval. Buena prueba de ello son sus estudios sobre el agustinismo, el franciscanismo y escotismo, sin olvidar a las corrientes averroístas. Pero quizás la figura de Tomás de Aquino ha centrado su atención de modo particular. No podemos catalogarlo, pues, como un pensador «tomista» en sentido estricto, sino más bien como un medievalista que ha contribuido a un mejor conocimiento del pensamiento tomista.

A él le debemos diversas traducciones al castellano de obras de Santo Tomás que continúan siendo hoy de consulta. Así sucede, por ejemplo, con la traducción anotada de los escritos catequéticos. ${ }^{16}$ Posteriormente editó la versión del Compendio de teología, un trabajo cuidadoso al que dedicó un particular esfuerzo. ${ }^{17}$ Recientemente ha sacado a la luz el comentario tomasiano al libro de Job y ha editado, con amplias paráfrasis, el comentario a los tres primeros capítulos jobianos. ${ }^{18}$ Además, también se hizo cargo de la traducción castellana de la célebre obra del dominico James Weisheipl sobre Santo Tomás, referencia obligada todavía en la actualidad para introducirse en el pensamiento del Aquinatense. ${ }^{19}$

Saranyana no sólo ha hecho más accesible el pensamiento tomasiano sino que ha propuesto - junto a otros autores - una línea de renovación de la tradición tomista en la línea apuntada anteriormente de la «regionalización de la Filosofía». Para nuestro autor, a lo largo del siglo XX coexistieron en la tradición tomista dos modos de leer la obra de Tomás de Aquino: por un lado se encontraba un modo de exposición más tradicional, cultivado por los neotomistas, para quienes el marco histórico era algo secundario y accidental, que podía incluso llevar a relativizar la originalidad de la síntesis tomasiana; por otro lado se encontraban los nuevos tomistas, que apostaban por un acercamiento contextualizado al Angélico. Los nuevos tomistas, con una hermenéutica más en sintonía con el historicismo que se respiraba en las

15 Josep-Ignasi Saranyana, Filosofía y teología en el Mediterráneo occidental (1263-1490), Eunsa (Col. «Historia de la Iglesia», 35), Pamplona. 2003.

16 Santo Tomás de Aquino. Escritos de Catequesis, Eds. Rialp, Madrid, 1975 (2. a ed., 1976; 3. ${ }^{\text {ed., }}$ 2000). Nueva edición, con nuevo estudio preliminar y nuevas notas: Tomás de Aquino. Obras catequéticas, Eds. Eunate, Pamplona, 1995.

17 Santo Tomás de Aquino. Compendio de Teología. (Estudio preliminar, traducción y notas), Rialp, Madrid, 1980.

18 Josep-Ignasi Saranyana, Por qué sufren los buenos y triunfan los malos. Comentario literal de Tomás de Aquino al libro de Job (capítulos 1-3), Servicio de Publicaciones de la Universidad de Navarra («Cuadernos de Anuario Filosófico. Serie Universitaria», n. 222), Pamplona, 2010.

19 Cfr. James A. Weisheipl, Tomás de Aquino. Vida, obras y doctrina, Eunsa, Pamplona, 1994. 
universidades europeas de esos años, leían a Aquino en el siglo XIII y se aprovechaban mejor de la perennidad de sus aportaciones porque lo entendían mejor.

Este bosquejo de algunos aspectos de la investigación de este reconocido medievalista no puede hacer justicia a su producción extensa y fecunda. Producción, por lo demás, todavía abierta. Por otro lado, se dejan de lado otros aspectos sobresalientes de la rica y polifacética personalidad del profesor Saranyana. Habría que mencionar, por ejemplo, su personalidad de investigador «curioso», infatigable y viajero; así como a su talante abierto y cortés. Habría que referirse también a su faceta de conferenciante brillante y profesor apasionado; a su capacidad de trabajo y de acción (tan difícil de encontrar entre los académicos); su pronta disponibilidad sacerdotal; su conversación estimulante y cordial. En definitiva: un maestro universitario.

José Ángel García Cuadrado Facultad Eclesiástica de Filosofía Universidad de Navarra jagarcia@unav.es 